\title{
Overexpression of Glutamine:Fructose-6-Phosphate Amidotransferase in Transgenic Mice Leads to Insulin Resistance
}

\author{
Leon F. Hebert, Jr., ${ }^{\star}$ Marc C. Daniels, ${ }^{*}$ Jianxin Zhou, ${ }^{*}$ Errol D. Crook, ${ }^{*}$ Ramona L. Turner, ${ }^{\star}$ Shakisha T. Simmons, \\ John L. Neidigh, ${ }^{\star}$ Jin-Su Zhu, ${ }^{\ddagger}$ Alain D. Baron, ${ }^{\ddagger}$ and Donald A. McClain ${ }^{\star}$ \\ *Veterans Administration Medical Center and Department of Medicine, University of Mississippi Medical Center, Jackson, Mississippi \\ 39211; and ${ }^{\ddagger}$ Veterans Administration Medical Center and Department of Medicine, Indiana University Medical Center, Indianapolis, \\ Indiana 46202
}

\begin{abstract}
The hexosamine biosynthetic pathway has been hypothesized to be involved in mediating some of the toxic effects of hyperglycemia. Glutamine:fructose-6-phosphate amidotransferase (GFA), the first and rate limiting enzyme of the hexosamine biosynthetic pathway, was overexpressed in skeletal muscle and adipose tissue of transgenic mice. A 2.4-fold increase of GFA activity in muscle of the transgenic mice led to weight-dependent hyperinsulinemia in random-fed mice. The hyperinsulinemic-euglycemic clamp technique confirmed that transgenic mice develop insulin resistance, with a glucose disposal rate of $68.5 \pm 3.5$ compared with $129.4 \pm 9.4$ $\mathrm{mg} / \mathrm{kg}$ per $\min (P<0.001)$ for littermate controls. The decrease in the glucose disposal rate of the transgenic mice is accompanied by decreased protein but not mRNA levels of the insulin-stimulated glucose transporter (GLUT4). These data support the hypothesis that excessive flux through the hexosamine biosynthesis pathway mediates adverse regulatory and metabolic effects of hyperglycemia, specifically insulin resistance of glucose disposal. These mice can serve as a model system to study the mechanism for the regulation of glucose homeostasis by hexosamines. (J. Clin. Invest. 1996. 98:930-936.) Key words: hexosamine biosynthesis • skeletal muscle • GLUT4 • glutamine:fructose-6-phosphate amidotransferase $\bullet$ hyperinsulinemia
\end{abstract}

\section{Introduction}

Insulin resistance is a hallmark of both insulin-dependent and non-insulin-dependent diabetes mellitus (IDDM and NIDDM) ${ }^{1}$ (1-3). This state is characterized by a decreased ability of insulin to stimulate glucose uptake and utilization in the hormone's target tissues, particularly skeletal muscle. In NIDDM insulin resistance at the postreceptor level may play a fundamental role in the pathogenesis of that disease (1). Additionally, in

Address correspondence to Donald A. McClain, Division of Endocrinology, 2500 N. State Street, Jackson, MS 39216. Phone: 601-9845525; FAX: 601-984-5769.

Received for publication 17 November 1995 and accepted in revised form 31 May 1996.

1. Abbreviations used in this paper: GFA, glutamine:fructose-6-phosphate amidotransferase; GlcN-6-P, glucosamine-6-phosphate; GLUT4, insulin-stimulated glucose transporter; NIDDM, non-insulin-dependent diabetes mellitus; UDP-HexNAc, UDP-N-acetyl hexosamine.

The Journal of Clinical Investigation

Volume 98, Number 4, August, 1996, 930-936 both IDDM and NIDDM insulin resistance can result from hyperglycemia itself $(2,3)$. How target tissues might be sensing and responding to hyperglycemia, however, is unknown. It has been suggested recently that glucose flux through the hexosamine biosynthetic pathway might be responsible for some of the adverse regulatory effects of excessive glucose (4). For example, glucosamine has been shown to be much more potent than glucose in inducing insulin resistance in cultured adipocytes, and inhibitors of hexosamine synthesis block the ability of glucose to cause insulin resistance (5).

Glutamine:fructose-6-phosphate amidotransferase (GFA), the first and rate-limiting enzyme in the hexosamine biosynthetic pathway, transfers the amide group from glutamine to fructose-6-phosphate to form glucosamine-6-phosphate (GlcN6-P), a precursor of uridine diphosphate- $N$-acetyl-glucosamine. We have demonstrated that overexpression of GFA in Rat-1 fibroblasts results in insulin resistance, i.e., a rightward shift in the insulin dose response curve for stimulation of glycogen synthase $(6,7)$. Moreover, these cells exhibit increased sensitivity to the regulatory effects of glucose on glycogen synthase, suggesting that cellular sensing of glucose does operate through hexosamine metabolism.

To test the hypothesis that hexosamine metabolism is involved in insulin resistance in the intact organism, we have examined glucose homeostasis in transgenic animals that overexpress GFA in muscle and adipose tissue. We find that increased activity of GFA in the target tissues of insulin-stimulated glucose disposal causes an increase in random fed insulin levels in the transgenic animals compared with control littermates. This hyperinsulinemia is sex and weight dependent and not seen in the fasting state. Insulin resistance in the transgenic mice was confirmed with the use of the hyperinsulinemic-euglycemic clamp and appears to be caused by a decrease in protein levels of the insulin-stimulated glucose transporter (GLUT4). These results support the hypothesis that the hexosamine biosynthesis pathway is used as a glucose sensor for the regulation of insulin-stimulated glucose uptake.

\section{Methods}

Creation of transgenic animals. Transgene expression is targeted to adipose tissue and cardiac and skeletal muscle with the GLUT4 promoter and transcription initiation site that are contained in a $2.1-\mathrm{kb}$ KpnI-HindIII fragment derived from the modified pHSS6 plasmid $(8,9)$. This fragment was ligated upstream of the 2.1-kb HindIIIBamHI GFA cDNA (10) and the 0.4-kb BamHI-XbaI SV40 polyA signal DNA in Bluescript SK $+/-$ phagemid (Stratagene Inc., La Jolla, CA). The transgene construct was excised from Bluescript with KpnI and XbaI (Fig. $1 A$ ), purified, and microinjected into one-cell mouse embryos that were then surgically reimplanted into pseudopregnant female mice at the University of Alabama Transgenic Facility (Birmingham, AL). 
A

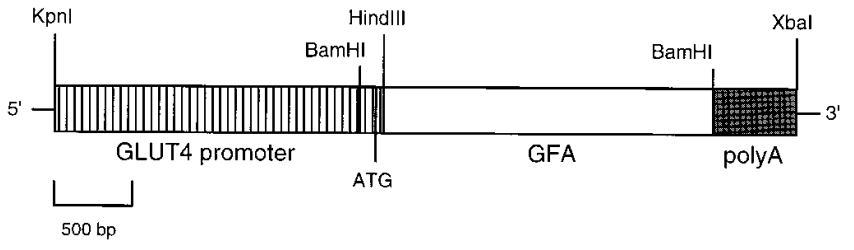

B

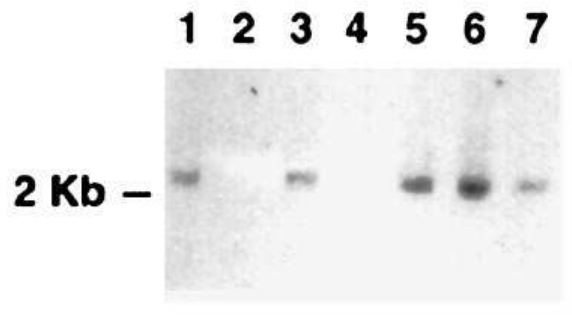

C

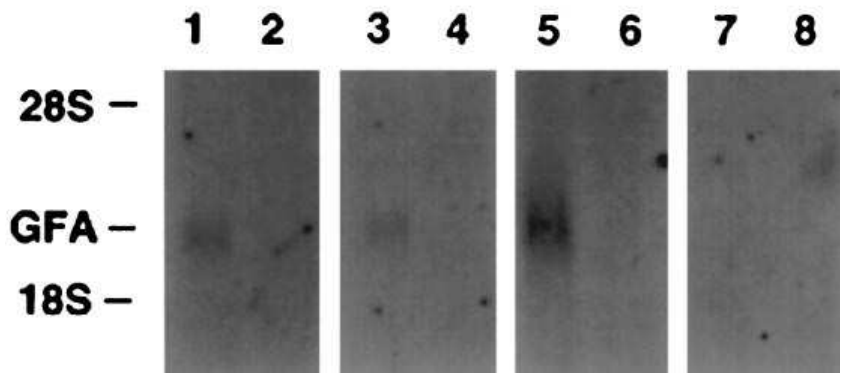

Figure 1. Creation of the transgene construct and confirmation of the transgenic line. $(A)$ The GLUT4 promoter and transcription initiation site are contained in a 2.1-kb KpnI-HindIII fragment (striped). This fragment is ligated upstream of the 2.1-kb HindIII-BamHI GFA cDNA (open) and the 0.4-kb BamHI-XbaI SV40 polyA signal DNA (shaded). (B) Chromosomal DNA extracted from tail tissue of each founder mouse was digested with BamHI and subjected to Southern analysis. Five founder mice; 1-1, 1-10, 2-11, 8-3, and 7-8; (lanes 1, 3, $5-7$, respectively) were found to have the $2.1-\mathrm{kb}$ BamHI-BamHI fragment that demonstrates the transgene is incorporated into their chromosomal DNA. $(C)$ Total RNA was extracted from skeletal muscle (lanes 1,3,5, and 7) and liver (lanes 2, 4,6, and 8) from transgenic 1-1 (lanes 1 and 2), 7-8 (lanes 3 and 4), 8-3 (lanes 5 and 6), and nontransgenic control mice (lanes 7 and 8 ) and subjected to Northern analysis. Expression of the transgene mRNA is seen in the muscle but not the liver of the founder mice 1-1, 7-8, and 8-3.

DNA and RNA analysis. Chromosomal tail DNA from offspring of the implanted females was tested for the presence of the transgene by Southern blot analysis. $10 \mu \mathrm{g}$ of chromosomal DNA of each founder mouse was digested with BamHI and subjected to electrophoresis in a 1.0\% agarose gel. The DNA was then transferred to nylon membrane (MagnaGraph; MSI, Westboro, MA) and hybridized with a 700-bp GFA cDNA probe. The probe was labeled with $\left[\alpha{ }^{32} \mathrm{P}\right] \mathrm{dCTP}$ and dATP (Amersham Corp., Arlington Heights, IL) by use of a random priming kit (Boehringer Mannheim Biochemicals, Indianapolis, IN). After hybridizing the membrane with the probe for $16 \mathrm{~h}$ at $42^{\circ} \mathrm{C}$
(11), the membrane was washed once in $1.0 \times$ saline sodium citrate at room temperature for $20 \mathrm{~min}$, three times in $0.2 \times$ saline sodium citrate at $65^{\circ} \mathrm{C}$ for $30 \mathrm{~min}$ and exposed to film at $-80^{\circ} \mathrm{C}$ for $1 \mathrm{wk}$.

Total RNA was obtained from skeletal muscle, adipose tissue, or liver by the guanidinium isothiocyanate method (12), and RNA samples $(20 \mu \mathrm{g})$ were electrophoresed in a $1.0 \%$ agarose-formaldehyde gel. The RNA was then transferred to nylon membrane and probed for the human GFA cDNA as stated above. RNA was also probed for GLUT4 and $\beta$-actin using single stranded oligonucleotides specific for murine GLUT4 and $\beta$-actin mRNA (13) that were labeled at the $5^{\prime}$ end using $\left(\gamma^{-32} \mathrm{P}\right)$ ATP (Amersham Corp.) and polynucleotide kinase (Promega Corp., Madison, WI). The blots were then processed as stated above. Autoradiographs were analyzed densitometrically using an Eagle Eye II Still Video System (Stratagene Inc.) and ONE-Dscan one-dimensional electrophoresis analysis software (Scanalytics, Billerica, MA).

GFA activity assay. GFA activity was measured as previously described by Crook et al. (6). Hindlimb muscle from fasted animals that had been frozen in liquid nitrogen and stored at $-80^{\circ} \mathrm{C}$ until time of the assay was placed in $1.0 \mathrm{ml}$ of extraction buffer $(100 \mathrm{mM} \mathrm{KCl}, 1$ $\mathrm{mM}$ EDTA, and $50 \mathrm{mM}$ Na phosphate; $\mathrm{pH}$ 7.5). The samples were then homogenized (VirTis homogenizer; VirTis Co., Gardiner, NY) and sonicated (50 Sonic Dismembrator; Fisher Scientific, Tustin, CA) at setting 7 for $10 \mathrm{~s}$ at $4^{\circ} \mathrm{C}$. After centrifugation at $60,000 \mathrm{~g}$ for $20 \mathrm{~min}$ at $4^{\circ} \mathrm{C}, 240 \mu \mathrm{g}$ of protein of the supernatant cytoplasmic extract were incubated with $12 \mathrm{mM}$ fructose-6-phosphate, $12 \mathrm{mM}$ glutamine, 40 $\mathrm{mM} \mathrm{NaH}_{2} \mathrm{PO}_{4}, 1 \mathrm{mM}$ EDTA and $1 \mathrm{mM}$ DTT (final volume $100 \mu \mathrm{l}$ ), for $45 \mathrm{~min}$ at $37^{\circ} \mathrm{C}$. The reaction was stopped and protein precipitated by the addition of $50 \mu \mathrm{l} 1 \mathrm{M}$ perchloric acid and incubation on ice for $10 \mathrm{~min}$. After centrifugation at $16,000 \mathrm{~g}$ for $10 \mathrm{~min}, 145 \mu \mathrm{l}$ of supernatant were extracted with $258 \mu \mathrm{l}$ of tri- $n$-octylamine:1,1,2-trichloro-trifluoroethane (1:4), and the 120- $\mu$ l aqueous phase was then ready for HPLC analysis. GlcN-6-P generated in the reaction was detected by derivatization of the sample with $2 \mathrm{vol} o$-phthaldialdehyde (OPA) reagent ( $4 \mathrm{mg}$ OPA in $50 \mu \mathrm{l}$ ethanol added to $5 \mathrm{ml} 0.1 \mathrm{M}$ sodium borate, $\mathrm{pH}$ 9.7, and $10 \mu \mathrm{l}$ 2-mercaptoethanol) for $1 \mathrm{~min}(14,15)$. Samples were then neutralized with $120 \mu \mathrm{l} 0.1 \mathrm{M}$ sodium phosphate $(\mathrm{pH} 7.4)$, filtered, and separated over a reverse-phase $\mathrm{C} 18$ column $(25 \mathrm{~cm} \times 4.6$ $\mathrm{mm}$; Phase Separations Inc., Norwalk, CT). Absorbance of the sample eluent was analyzed fluorometrically and peak area was integrated. OPA-derivatized GlcN-6-P standards were run separately to determine retention time and generate a standard curve to correlate area to activity. Activity is expressed as $\mathrm{U} / \mathrm{mg}$ protein where $1 \mathrm{U}$ represents the generation of $1 \mathrm{pmol} \mathrm{GlcN-6-P/min}$.

Analysis of nucleotide-linked hexosamines. Levels of uridine-diphosphate- $N$-acetyl hexosamine (UDP-HexNAc), products of the hexosamine biosynthesis pathway, were measured in muscle tissue as described by Robinson et al. (16). Hindlimb muscle $(\sim 0.25 \mathrm{~g})$ from fasted animals was homogenized at $4^{\circ} \mathrm{C}$ in 4 vol of perchloric acid $(300 \mathrm{mM})$. The precipitates were pelleted by centrifugation $(10,000 \mathrm{~g}$, $15 \mathrm{~min}, 4^{\circ} \mathrm{C}$ ), and the acid was extracted from the supernatants with 2 vol of tri- $n$-octylamine:1,1,2-trichloro-trifluoroethane (1:4). The aqueous phase was stored at $-80^{\circ} \mathrm{C}$ until analysis the next day by HPLC. The extracts were filtered $(0.45 \mu \mathrm{m})$, and HPLC was performed on a Spherisorb amino column $(25 \mathrm{~cm} \times 4.6 \mathrm{~mm}$, Phase Separations Inc.) eluted with a concave gradient from $80 \mathrm{mM}$ potassium phosphate (pH 2.8), 35\% acetonitrile, to $800 \mathrm{mM}$ potassium phosphate ( $\mathrm{pH} 3.6$ ) over $45 \mathrm{~min}$ at a flow rate of $1 \mathrm{ml} / \mathrm{min}$ (17). UDP-HexNAc levels were quantified by UV absorption (A254), compared with external standards and corrected for tissue weight.

Analytical procedures. Male mice were either fed ad libitum or fasted overnight $(18 \mathrm{~h})$ before blood samples were collected from the brachial artery. Hemoglobin A1c percentages and glucose concentrations were measured using diagnostic reagent kits (Sigma Chemical Co., St. Louis, MO). Insulin concentrations were measured by RIA using porcine standards (Binax, Portland, ME).

Hyperinsulinemic-euglycemic clamp. All experiments were performed in awake, weight matched, non sedated transgenic and litter- 
mate control mice using a similar clamp technique as described by Ren et al. (18). Experimental protocols were approved by the Animal Use Committee of the University of Mississippi Medical center. Catheters were implanted into the right internal jugular vein of transgenic and control mice. The animals were allowed to recover from surgery the following day then were fasted $18 \mathrm{~h}$ before the experiment. $\left[3-{ }^{3} \mathrm{H}\right]$ glucose (New England Nuclear, Boston,MA) was infused throughout the clamp experiment to determine the glucose turnover rate. A priming dose of $0.33 \mu \mathrm{Ci}$ in $11.2 \mu \mathrm{l}$ saline $(0.9 \%)$ was infused followed by continuous infusion at a rate of $0.08 \mu \mathrm{Ci} / \mathrm{min}(2.5 \mu \mathrm{l} / \mathrm{min})$ for the duration of the experiment. After $30 \mathrm{~min}$, the animals were infused with recombinant human insulin (HumulinR; Eli Lilly \& Co., Indianapolis, IN) at a rate of $20 \mathrm{mU} / \mathrm{kg}$ per min while $50 \%$ dextrose was infused by a variable infusion pump (Harvard Apparatus Inc., South Natick, MA). Whole blood samples $(3 \mu \mathrm{l})$ were collected every 5-10 min from tail bleeds and measured by the glucose oxidase method (Glucometer Elite; Bayer Corp., Tarrytown, NY). Blood glucose concentrations and glucose infusion rates were clamped at steady state for a minimum of $20 \mathrm{~min}$. Serum samples were then taken for calculating insulin levels and hepatic glucose output. The rate of glucose appearance or glucose turnover rate was calculated by dividing the $\left[3-{ }^{3} \mathrm{H}\right]$ glucose infusion rate (disintegrations per minute/ $\mathrm{kg}$ per min) by the mean serum glucose specific activity (disintegrations per minute/mg glucose). The rate of hepatic glucose production
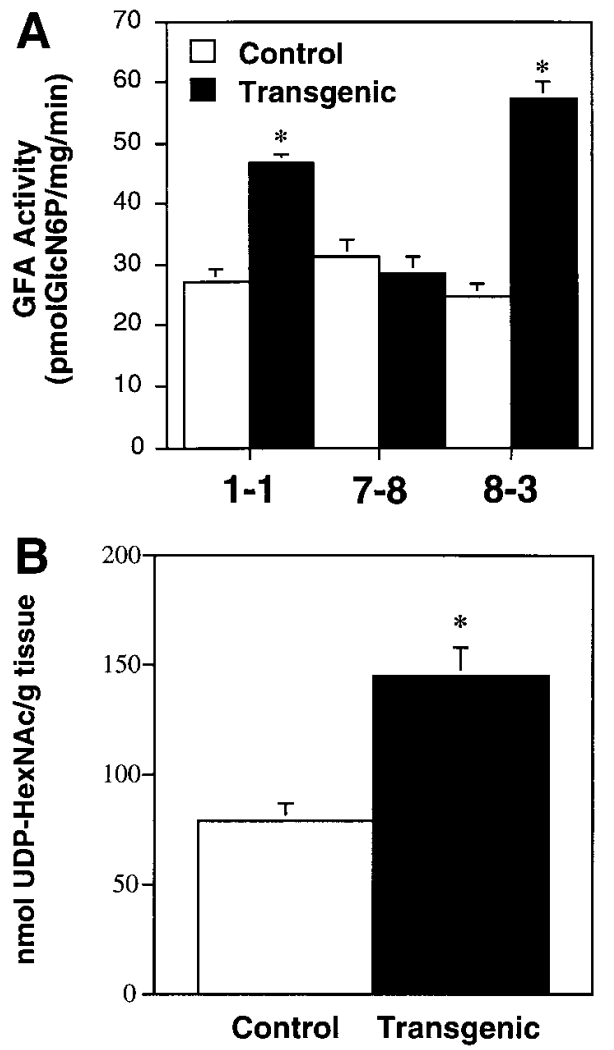

Figure 2. Activity of the hexosamine biosynthetic pathway in muscle. (A) GFA activity was greatest in the transgenic mice of the 8-3 founder line with a 2.3-fold increase over control. Transgenic mice from the 1-1 founder line have a 1.5-fold increase in GFA activity over control but GFA activity of transgenic mice from the 7-8 do not differ from their controls ( $n=3$ /group for 1-1 and 7-8 lines, $n=6$ / group for 8-3 line; $* P<0.01$ ). (B) UDP-HexNAc levels were quantified in quadricep muscle of fasted transgenic and control mice of the 8-3 founder line. Muscle from transgenic mice was found to have a twofold higher level of UDP-HexNAc compared with levels from muscle of control mice $\left(n=3\right.$ /group; $\left.{ }^{*} P<0.05\right)$. was calculated by subtracting the glucose infusion rate from the glucose turnover rate. Glucose disposal rates were calculated by subtracting the hepatic glucose output from the glucose infusion rate.

GLUT4 protein determination. Transgenic and control hindlimb muscle from age- and weight-matched littermates was homogenized in buffer containing $25 \mathrm{mM}$ Hepes (pH 7.4), 4 mM EDTA, $1 \%$ Triton $\mathrm{X}-100$, and $1 \mu \mathrm{M}$ each of leupeptin, pepstatin, and aprotinin (Sigma Chemical Co.). $100 \mu \mathrm{g}$ of protein of each sample were electrophoresed by $10 \%$ SDS-PAGE (19) and transferred to a nitrocellulose membrane. The blot was blocked for $1 \mathrm{~h}$ at room temperature in $1 \times$ TBS with $5 \%$ nonfat milk, and probed overnight with a polyclonal antibody for GLUT4 (East Acres Biologicals, Southbridge, MA). The following day the membrane was washed three times for $30 \mathrm{~min}$ with $1 \times$ TBS, $0.05 \%$ Tween-20, incubated with ${ }^{125} \mathrm{I}$-protein A (ICN, Costa Mesa, CA), washed for another $30 \mathrm{~min}$, and exposed to film at $-80^{\circ} \mathrm{C}$ for 1-4 d. Immunoblots were analyzed densitometrically as stated above.

Statistical analysis. Linear regression was used to determine the degree of association between insulin and glucose concentrations and analysis of variance was applied to test if these regression lines were significantly different. All other values are presented as the means \pm standard error. Student's $t$ test was performed for comparisons of means between two groups.

\section{Results}

Determination of transgene incorporation and transcription in mouse tissue. Genomic DNA purified from tail tissue of the founder mice was digested with BamHI and analyzed by Southern blotting with a human GFA cDNA probe. Genomic DNA from five of the founder mice (1-1, 1-10, 2-11, 7-8, and 8-3) exhibited a 2.2-kb BamHI restriction fragment specific to the transgene that hybridized to the GFA probe (Fig. $1 B$ ). Northern analysis of total RNA from muscle and liver tissue of transgenic and control mice revealed expression of the transgene in muscle of three of the five original founder lines (1-1, 7-8, and 8-3; Fig. $1 C$ ). The transgene was not detected in liver. Transgene expression was also seen in adipose tissue from epididymal fat pads (data not shown). Endogenous GFA mRNA is significantly larger than the transgenic mRNA (10) and is not visualized in these blots due to the stringent washing conditions designed to detect only the human derived transgene.

Increased GFA activity and UDP-N-acetyl hexosamines in the transgenic mice. Overexpression of GFA activity in the Northern blot-positive mice was confirmed using an in vitro assay for GFA. Cytoplasmic extracts of skeletal muscle from each of the three lines were incubated with fructose-6-phosphate and glutamine, and GlcN-6-P production was quantified. Fig. $2 A$ shows the increase in GFA activity in muscle tissue of the three mRNA positive lines compared with nontransgenic

Table I. Blood HbAlc and Serum Glucose and Insulin Levels in Fasted Transgenic Mice and Nontransgenic Controls

\begin{tabular}{lcc}
\hline & Transgenic & Control \\
\hline Weight (grams) & $29.7 \pm 0.8$ & $30.8 \pm 0.9$ \\
Hemoglobin A1c $(\%)$ & $2.58 \pm 0.06$ & $2.48 \pm 0.08$ \\
Fasting glucose $(\mathrm{mg} / \mathrm{dl})$ & $91 \pm 7$ & $93 \pm 10$ \\
Fasting insulin $(\mu \mathrm{U} / \mathrm{ml})$ & $8.6 \pm 0.5$ & $7.7 \pm 0.3$
\end{tabular}

Mice were fasted for $18 \mathrm{~h}$ before being bled via the brachial artery. Values represent the mean \pm standard error for six animals per group. 

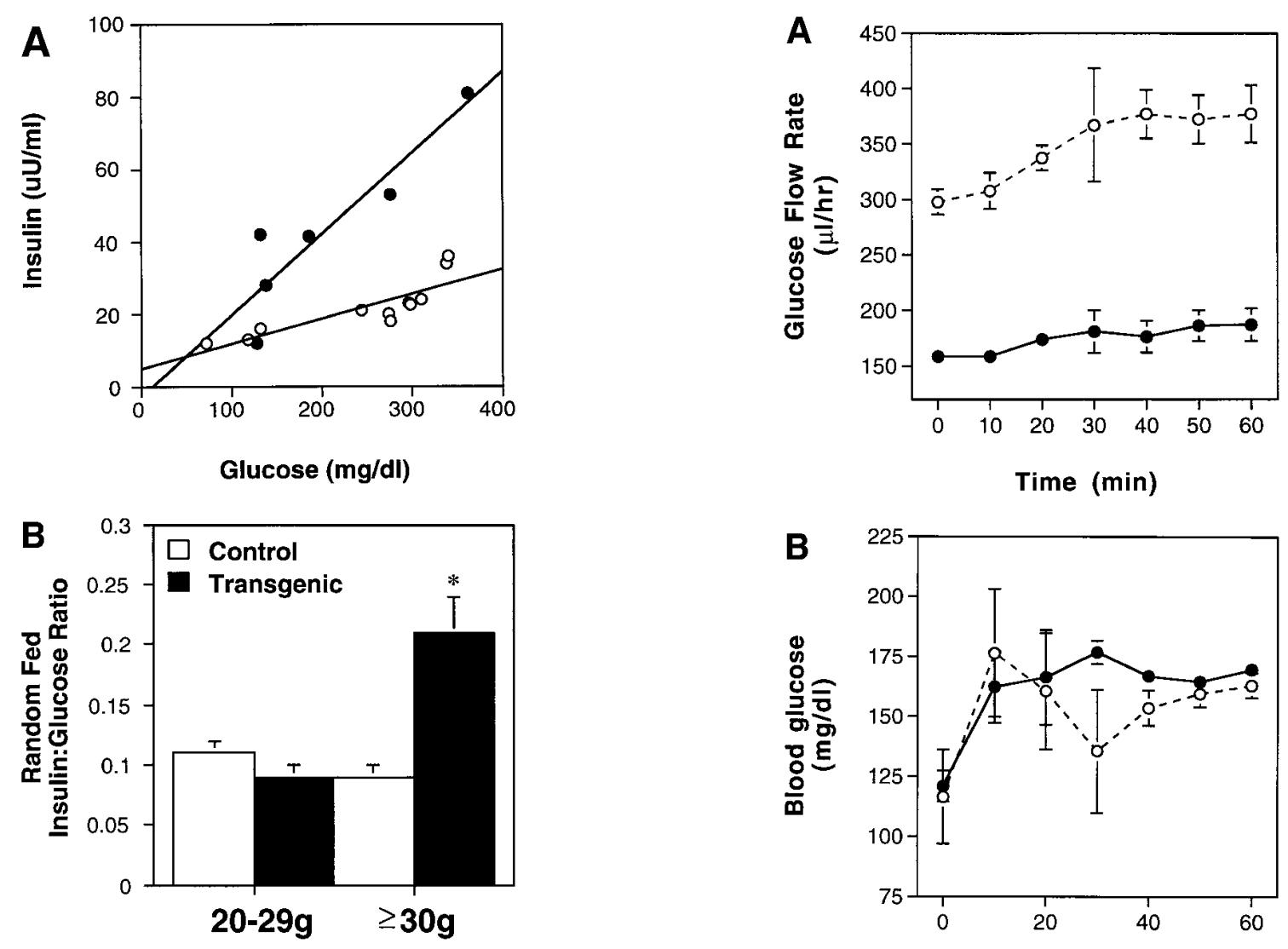

Figure 3. Effects of increased GFA actvity on random-fed insulin and glucose levels of 8-3 transgenic and control mice. $(A)$ Serum glucose and insulin levels from male mice weighing $\geq 30$ grams were measured and insulin levels are plotted as a function of glucose concentration. Both groups of mice show a correlation between insulin and glucose levels (Transgenic [@] $n=6, r=0.909, P<0.01$; Control $[\bigcirc]$ $n=11, r=0.845, P<0.001)$. The transgenic mice are hyperinsulinemic compared with their control littermates as seen in the greater slope of the transgenic regression line. The difference between these two regression lines is significantly different $(P<0.05)$. $(B)$ The insulin/glucose ratios show that the degree of hyperinsulinemia and apparent insulin resistance in the transgenic mice is weight dependent. Insulin/glucose ratios of lighter $(<30$ grams) transgenic and control littermates do not differ significantly. However the heavier transgenic mice have a higher insulin/glucose ratio than their control littermates $(n=6 /$ group; $* P<0.05)$.

littermate controls. Founder lines 1-1 and 8-3 have increased GFA activity, 1.5- and 2.4-fold, respectively, while founder line 7-8 has no increased activity. Based on these results, the 8-3 founder line was the line chosen for further studies. To determine if the increased GFA seen in the in vitro assay resulted in increased hexosamine synthesis in vivo, UDP-HexNAc levels were assayed. Fig. $2 B$ shows that UDP-HexNAc levels in skeletal muscle from transgenic mice of the 8-3 line are twofold greater than those in control littermates.

Hemoglobin A1c, serum glucose, and insulin levels. As seen in Table I, there were no significant differences in weight, glycated hemoglobin, fasting glucose or fasting insulin levels between transgenic mice and littermate controls. In mice that were fed ad libitum however male transgenic mice were hyperinsulinemic compared with their control littermates. In Fig. 3 $A$, the serum insulin level is plotted as a function of the blood
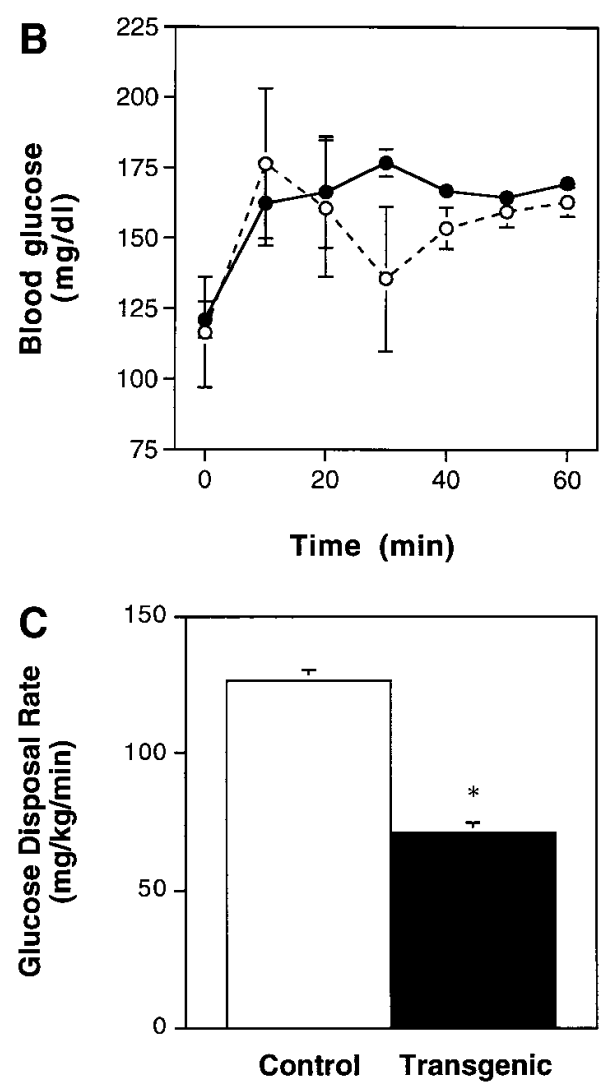

Figure 4. Hyperinsulinemic-euglycemic clamp of adult mice from the 8-3 founder line. (A) Values represent the glucose infusion rates used to maintain a constant blood glucose value of $165 \mathrm{mg} / \mathrm{dl}$ during the procedure (transgenic [@], control [O]; $n=4 /$ group). (B) Blood glucose values of the transgenic $(\bullet)$ and control $(O)$ mice during the procedure ( $n=4$ /group). (C) Based on the weight of the animal, glucose infusion rate, and hepatic glucose output, glucose disposal rates were calculated at the end of the experiment. $(n=4 /$ group; $* P<0.01)$.

glucose concentration in the random fed mice weighing 30 grams or over; the transgenic mice exhibit higher insulin levels compared to their littermate controls for similar glucose concentrations. Although this trend of higher insulin/glucose ratios is not evident in the male transgenic mice weighing $<30$ grams (Fig. $3 \mathrm{~B}$ ), transgenic mice weighing $<30$ grams did have higher random fed serum glucose levels $(271 \pm 22$ vs $192 \pm$ $18 \mathrm{mg} / \mathrm{dl} ; n=8 /$ group; $P<0.05)$ and a trend of higher insulin 
levels than their sex- and weight-matched control littermates (24.5 \pm 4.7 vs $21.4 \pm 3.3 \mathrm{mU} / \mathrm{ml})$.

Glucose disposal rates during the hyperinsulinemic-euglycemic clamp. Both male and female 3-6-mo-old transgenic mice were confirmed to be insulin resistant with the use of the hyperinsulinemic-euglycemic clamp. Transgenic and control weight-matched littermates, $23.4 \pm 0.8$ and $22.8 \pm 0.9$ grams, respectively, had catheters implanted in the right internal jugular vein. $2 \mathrm{~d}$ later the awake nonsedated animals were infused with $\left[3-{ }^{3} \mathrm{H}\right]$ glucose, insulin at a constant rate of $20 \mathrm{mU} / \mathrm{kg}$ per min, and unlabeled glucose at a variable rate (Fig. $4 A$ ). Based on preliminary experiments, initial glucose infusion rates were predetermined to minimalize fluctuations in blood glucose levels (data not shown). Blood glucose levels were clamped at 165 $\mathrm{mg} / \mathrm{dl}$ for the final $20 \mathrm{~min}$ of the procedure (Fig. 4 B). Serum insulin levels at the end of the clamp were $827 \pm 212 \mathrm{mU} / \mathrm{ml}$, and hepatic glucose output was calculated to be completely

\section{A}
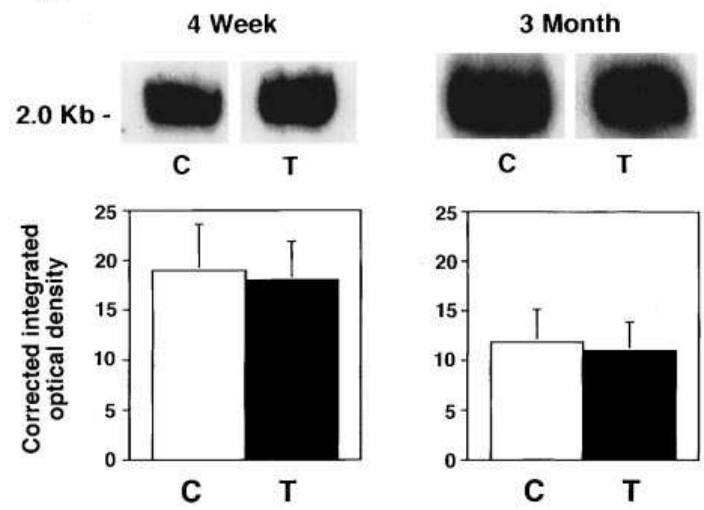

B
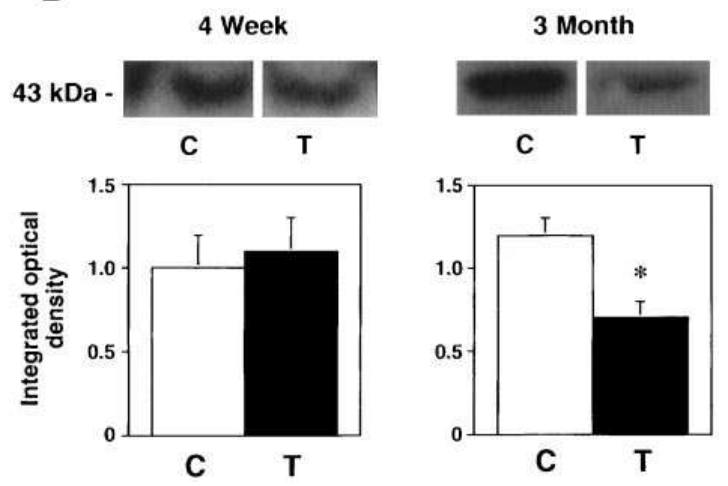

Figure 5. Muscle GLUT4 expression in mice of the 8-3 founder line. Total RNA $(A)$ and protein $(B)$ from hindlimb muscle of 4 -wk and 3-mo-old transgenic $(T)$ and control $(C)$ mice were probed for GLUT4 expression (representative autoradiograms are shown). Densitometry was performed and the integrated optical density of the bands corresponding to the GLUT4 mRNA and protein was compared between transgenic and control samples. GLUT4 mRNA levels were found not to differ significantly between transgenic and control muscle in either age group when corrected to $\beta$-actin mRNA levels (4-wk-old mice, $n=6$ /group; 3 -mo-old mice, $n=4$ /group). GLUT4 protein levels were also found not to differ between young transgenic and control mice ( $n=6$ /group). However, GLUT4 levels in the 3-moold transgenic mice were significantly decreased compared with those of the control mice $(n=6 /$ group; $* P<0.05)$. suppressed at this rate of insulin infusion (data not shown). Fig. $4 C$ shows that the insulin-stimulated glucose disposal rate of the transgenic mice is only $53 \%$ of that of the controls $(68.5 \pm 3.5$ vs $129.4 \pm 9.4 \mathrm{mg} / \mathrm{kg}$ per $\mathrm{min})$. This same decrease in glucose disposal rate was seen in transgenic and control mice clamped in the blood glucose range of 100-180 mg/dl (data not shown). A similar 58\% decrease in glucose disposal rate was seen in transgenic mice of the 1-1 line that had increased muscle GFA activity; no decrease was seen in transgenic mice of the 7-8 line that showed control levels of muscle GFA activity ( $n=4$, data not shown).

GLUT4 expression. A possible mechanism for decreased glucose disposal observed in the transgenic mice would be decreased levels of GLUT4. This could be either due to disruption of endogenous GLUT4 expression by the transgene or due to a regulatory effect of increased hexosamine synthesis. A positional effect of the transgene is unlikely due to the finding of insulin resistance in two separate founder lines of the transgenic mice (see above). An effect of the transgene on transcription of endogenous GLUT4 was ruled out by the finding of normal GLUT4 mRNA levels in skeletal muscle of young $(4 \mathrm{wk})$ or older $(3 \mathrm{mo})$ mice (Fig. $5 \mathrm{~A})$. Skeletal muscle GLUT4 protein levels were also found not to differ between young transgenic and control mice (Fig. 5 B). However, in older transgenic mice GLUT4 levels were $42 \%$ lower than those observed in control mice (Fig. 5 B).

\section{Discussion}

The hexosamine biosynthetic pathway has been hypothesized to be involved in mediating some of the toxic effects of hyperglycemia. Thus far, strategies to study the effects of increased flux of hexosamine synthesis in the whole animal, skeletal muscle, and adipose tissue have involved infusions and treatment with glucose and/or glucosamine (4, 5, 20-23). We have studied the role of this pathway in the whole animal by overexpressing GFA, the first and rate-limiting enzyme in the hexosamine biosynthetic pathway, in the specific tissues of insulin-stimulated glucose disposal. This was accomplished in transgenic animals by placing GFA expression under control of the GLUT4 promoter/enhancer DNA sequence. The GLUT4 promoter allows GFA to be overexpressed only in the tissues involved in insulin-stimulated glucose disposal. It has been shown that the GLUT4 promoter leads to relatively modest levels of transgene expression (8); thus the resulting two- to threefold increase in hexosamine flux might be expected to be in the range of changes that would be seen in physiologic hyperglycemia. This strategy would allow us to study the effects of increased flux through the hexosamine biosynthetic pathway without the multiple effects that can occur when high concentrations of glucosamine are infused, including inhibition of glucokinase (23) and protein glycosylation (24).

It was predicted that overexpression of GFA in muscle and fat tissue would increase glucose flux through the hexosamine biosynthetic pathway, mimicking the effects of hyperglycemia on hexosamine flux but in the absence of elevated glucose concentrations. If hexosamine flux is used to sense glucose, these tissues should then exhibit a decrease in insulin-stimulated glucose uptake as they do when exposed to excess glucose. This insulin resistance would be manifest as hyperglycemia and/or hyperinsulinemia in the fed state with no effect on fasting 
blood glucose due to the regulation of fasting blood glucose by the normally functioning liver that does not express the transgene. As predicted, the transgenic mice showed no differences in fasting serum glucose and insulin and hemoglobin A1c levels when compared with their control littermates. However at the higher glucose levels seen in random fed mice, the mice weighing 30 grams or more were significantly hyperinsulinemic compared to their weight- and sex-matched littermate controls. Although the smaller mice trended toward hyperinsulinemia and hyperglycemia, the hyperinsulinemia was statistically significant only in heavier transgenic male mice. The age- and weight-associated insulin resistance is reminiscent of human insulin resistance and NIDDM. Similar sex- and weightassociated expression of diabetic traits in rodent animal models has been described previously and may be due to the protective effects of estrogens on the development of insulin resistance and diabetes (25). Insulin resistance brought about by overexpression of GFA in these transgenic mice was confirmed with the hyperinsulinemic-euglycemic clamp. The increased sensitivity of this technique allowed us to demonstrate significant insulin resistance even in the smaller mice and female mice as well.

The mechanism for hexosamine-induced insulin resistance is not known but appears to be due to a decrease in total GLUT4 levels. Decreased GLUT4 levels are also seen in several animal models of chronic hyperglycemia such as in the streptozotocin treated diabetic rat and the Zucker ZDF/Drt-fa rat (26-28). Decreased GLUT4 levels such as are seen in these animal models are not observed in human NIDDM where total GLUT4 levels are normal but GLUT4 function or translocation is impaired $(29,30)$. On the other hand, GLUT4 levels do correlate with insulin sensitivity in nondiabetic humans (31). Animals acutely infused with glucosamine also showed insulin resistance that is caused by decreased translocation without alterations in total GLUT4 levels (23). The reason for these differences, whether they reflect species differences in the response to hyperglycemia or whether they reflect differences in acute versus chronic responses to increased hexosamine flux, are not yet known. The decreased GLUT4 levels in these transgenic mice are unlikely to be due to a positional effect of the transgene because insulin resistance was seen in two independently derived founder lines. GLUT4 mRNA levels do not differ between the transgenic and control mice. Thus the effect of GFA overexpression is not transcriptional and is not an artifact of competition by the GLUT4 promoter-driven transgene for limiting amounts of transcription factors used in endogenous GLUT4 expression. In further support of this, previous studies of transgene expression driven by the GLUT4 promoter revealed no change in the expression of endogenous GLUT4 (8; Pessin, J.E., personal communication).

Overexpression of GFA does decrease GLUT4 protein levels as the mouse ages. Young transgenic mice show no difference in GLUT4 protein levels compared with control littermates, but GLUT4 protein levels are significantly decreased in the older transgenic mice compared with control littermate. A relationship between decreased GLUT4 and insulin resistance is suggested but not proven by these data; the young mice are too small to study by the euglycemic clamp technique. Future studies using hindlimb perfusion will allow us to study the effects of GFA overexpression on glucose homeostasis in these younger mice and to observe the temporal evolution of the insulin resistance and its relation to GLUT4 levels.
In conclusion, we have shown that overexpression of GFA, the rate limiting enzyme in hexosamine synthesis, in transgenic mice results in insulin resistance for insulin-stimulated glucose disposal. These data further support the hypothesis that the hexosamine biosynthetic pathway plays a role in glucose homeostasis at the cellular level in skeletal muscle and may be responsible for some of the adverse regulatory and metabolic effects of hyperglycemia. These mice represent an attractive model to study the effects of hexosamine flux on GLUT4 expression and glucose homeostasis. Expression of the transgene and the resulting two- to threefold increase in total GFA activity should not lead to grossly altered metabolite fluxes since it is estimated that normally hexosamine metabolism only accounts for $1-2 \%$ of cellular glucose utilization (4). Thus the abnormalities in glucose flux in these mice are likely to be highly targeted and specific. Further characterization of these mice as well as mice overexpressing GFA in other tissues such as liver and islet $\beta$-cells should further clarify the role hexosamines play in cellular sensing of glucose and the responses to hyperglycemia. Mice with these targeted changes will also allow the examination of the effects of tissue-specific insulin resistance. The mechanisms by which hexosamines may exert these effects remain obscure. The products of this pathway are used for protein glycosylation so that alterations in regulated $\mathrm{N}$ - or $O$-linked glycosylation could play a role. In particular, the widespread occurrence of cytosolic $O$-linked $N$-acetyl glucosamine on transcription factors, RNA polymerase (32), and nuclear pore proteins (33) and the fact that at least some of the effects of GFA overexpression are transcriptional (34) suggest one potential area for further study.

\section{Acknowledgments}

This work was supported by the Research Service of the Department of Veterans Affairs Medical Center, Jackson, MS.

\section{References}

1. Olefsky, J.M. 1993. Insulin resistance and the pathogenesis of non-insulin dependent diabetes mellitus: cellular and molecular mechanisms. Adv. Exp. Med. Biol. 334:129-150.

2. Rossetti, L., A. Giaccari, and R.A. DeFronzo. 1990. Glucose toxicity. Diabetes Care. 13:610-630.

3. Yki-Jarvinen, H. 1992. Glucose toxicity. Endocr. Rev. 13:415-431.

4. Marshall, S., V. Bacote, and R.R. Traxinger. 1991. Discovery of a metabolic pathway mediating glucose induced desensitization of the glucose transport system: role of hexosamine biosynthesis in the induction of insulin resistance. J. Biol. Chem. 266:4706-4712.

5. Garvey, W.T., J.M. Olefsky, S. Matthaei, and S. Marshall. 1987. Glucose and insulin co-regulate the glucose transport system in primary cultured adipocytes. J. Biol. Chem. 262:189-197.

6. Crook, E.D., M.C. Daniels, T.M. Smith, and D.A. McClain. 1993. Regulation of insulin-stimulated glycogen synthase activity by overexpression of glutamine:fructose-6-phosphate amidotransferase in rat-1 fibroblasts. Diabetes. 42:1289-1296

7. Crook, E.D., J. Zhou, M.C. Daniels, J.L. Neidigh, and D.A. McClain. 1995. Regulation of glycogen synthase by glucose, glucosamine, and glutamine: fructose-6-phosphate amidotransferase. Diabetes. 44:314-320.

8. Liu, M.L., A.L. Olson, W.S. Moye-Rowley, J.B. Buse, G.I. Bell, and J.E. Pessin. 1992. Expression and regulation of the human GLUT4/muscle-fat facilitative glucose transporter gene in transgenic mice. J. Biol. Chem. 267:11673-11676.

9. Buse, J.B., K. Yasuda, T.P. Lay, T.S. Seo, A.L. Olson, J.E. Pessin, J.G. Karam, S. Seino, and G.I. Bell. 1992. Human GLUT4/muscle-fat glucose-transporter gene. Diabetes. 41:1436-1445.

10. Zhou, J., J.L. Neidigh, R. Espinosa, M.M. LeBeau, and D.A. McClain. 1995. Human glutamine:fructose-6-phosphate amidotransferase: characterization of mRNA and chromosomal assignment to 2p13. Hum. Genet. 96:99-101.

11. Sambrook, J., E.F. Fritsch, and T. Maniatis. 1989. Molecular Cloning: A Laboratory Manual, 2nd edition. Cold Spring Harbor Laboratory, Cold Spring Harbor, New York. 9.52-9.55. 
12. Chirgwin, J.M., A.E. Przybyla, R.J. MacDonald, and W.J. Rutter. 1979. Isolation of biologically active ribonucleic acid from sources enriched in ribonuclease. Biochemistry. 18:5294-5299.

13. Trayhurn, P., J.S. Duncan, A. Nestor, M.E.A. Thomas, and D.V. Rayner. 1994. Chemiluminescent detection of mRNAs on northern blots with digoxigenin end-labeled oligonucleotides. Anal. Biochem. 222:224-230.

14. Aftring, R.P., P.N. Manof, and M.G. Buse. 1985. Catabolism of branch chained amino acids by diaphragm muscles in fasted and diabetic rats. Metab. Clin. Exp. 34:702-711.

15. Roth, M. 1971. Fluorenscence reaction for amino acids. Anal. Chem. 43: $880-882$.

16. Robinson, K.A., M.L. Weinstein, G.E. Lindenmayer, and M.G. Buse. 1995. Effects of diabetes and hyperglycemia on the hexosamine synthesis pathway in rat muscle and liver. Diabetes. 44:1438-1446.

17. Hothersall, J.S., R.P. Muirhead, C.E. Taylaur, S. Kunjara, and P. McLean. 1993. Changes in uridine nucleotides and uridine nucleotide sugars in diabetic rat lens: implications in membrane glycoprotein formation. Biochem. Med. Metab. Biol. 50:292-300.

18. Ren, J., B.A. Marshall, M.M. Mueckler, M. McCaleb, J.M. Amatruda, and G.I. Shulman. 1995. Overexpression of GLUT4 protein in muscle increases basal and insulin-stimulated whole body glucose disposal in conscious mice. $J$. Clin. Invest. 95:429-432.

19. Laemmli, U.K. 1970. Cleavage of structural proteins during the assembly of the head of bacteriophage T4. Nature (Lond.). 227:680-685.

20. Robinson, A.R., D.A. Sens, and M.G. Buse. 1993. Pre-exposure to glucosamine induces insulin resistance of glucose transport and glycogen synthesis in isolated rat skeletal muscles. Diabetes. 42:1333-1346.

21. Traxinger, R.R., and S. Marshall. 1992. Insulin regulation of pyruvate kinase activity in isolated adipocytes. J. Biol. Chem. 267:9718-9723.

22. Baron, A.D., J.S. Zhu, J.H. Zhu, H. Weldon, L. Maianu, and W.T. Garvey. 1995. Glucosamine induces insulin resistance in vivo by affecting GLUT4 translocation in skeletal muscle: implications for glucose toxicity. Diabetes. 44 (Suppl. 1): 49a. (Abstr.)

23. Balkan, B., and B.E. Dunning. 1994. Glucosamine inhibits glucokinase in vitro and produces a glucose-specific impairment of in vivo insulin secretion in rats. Diabetes. 43:1173-1179.
24. Counts, D.F., and W.N. Shaw. 1991. Effects of carbohydrate structure and concentration on the non-enzymatic glycosylation and subsequent crosslinking of collagen. Diabetes Res. 16:37-40.

25. Hamann, A., H. Benecke, Y. Le Marchand-Brustel, V.S. Susulic, B.B Lowell, and J.S. Flier. 1995. Characterization of insulin resistance and NIDDM in transgenic mice with reduced brown fat. Diabetes. 44:1266-1273.

26. Garvey, W.T. 1992. Glucose transport and NIDDM. Diabetes Care. 15: 396-417.

27. Bourey, R.E., L. Koranyi, D.E. James, M. Mueckler, and M.A. Permutt. 1990. Effects of altered glucose homeostasis on glucose transporter expression in skeletal muscle of the rat. J. Clin. Invest. 86:542-547.

28. Friedman, J.E., J.E. De Vente, R.G. Peterson, and G.L. Dohm. 1991 Altered expression of muscle glucose transporter GLUT-4 in diabetic fatty Zucker rats (ZDF/Drt-fa). Am. J. Physiol. 261:E782-E788.

29. Garvey, W.T., L. Maianu, J.A. Hancock, A.M. Golichowski, and A. Baron. 1992. Gene expression of GLUT4 in skeletal muscle from insulin-resistant patients with obesity, IGT, GDM, and NIDDM. Diabetes. 41:465-475.

30. Friedman, J.E., G.L. Dohm, N. Leggett-Frazier, C.W. Elton, E.B. Tapscott, W.P. Pories, and J.F. Caro. 1992. Restoration of insulin responsiveness in skeletal muscle of morbidly obese patients after weight loss. Effect on muscle glucose transport and glucose transporter GLUT4. J. Clin. Invest. 89:701-705.

31. Koranyi, L.I., R.E. Bourey, H. Vuorinen-Markkola, V.A. Koivisto, M. Mueckler, M.A. Permutt, and H. Yki-Jarvinen. 1991. Level of skeletal muscle glucose transporter protein correlates with insulin-stimulated whole body glucose disposal in man. Diabetologia. 34:763-765.

32. Reason, A.J., H.R. Morris, M. Panico, R. Marais, R.H. Treisman, R.S. Haltiwanger, G.W. Hart, W.G. Kelly, and A. Dell. 1992. Localization of O-GlcNAc modification on the serum response transcription factor. J. Biol. Chem. 267:16911-16921

33. Kearse, K.P., and G.W. Hart. 1991. Lymphocyte activation induces rapid changes in nuclear and cytoplasmic glycoproteins. Proc. Natl. Acad. Sci. USA. 88:1701-1705.

34. Daniels, M.C., P. Kansal, T.M. Smith, A.J. Paterson, J.E. Kudlow, and D.A. McClain. 1993. Glucose regulation of transforming growth factor-a expression is mediated by products of the hexosamine biosynthesis pathway. Mol. Endocrinol. 7:1041-1048. 